\title{
Hacia una más efectiva protección de la biodiversidad en España
}

\author{
Elena Espinosa ${ }^{1}$
}

En el conjunto de las políticas ambientales, la preocupación por el cambio climático y por la pérdida de biodiversidad destacan como dos de las cuestiones principales. No en vano ambas, estrechamente relacionadas por otra parte, se sitúan en el centro del interés de la acción política de los gobiernos nacionales y las organizaciones internacionales.

Como es sabido, el año 2010 se fijó como un horizonte de referencia para frenar la pérdida de biodiversidad y tratar así de reconducir una tendencia que algunos científicos señalan como la sexta ola de extinción de especies que, en esta ocasión, y a diferencia de las cinco anteriores, está estrechamente relacionada con la actividad humana.

Todo indica que la biodiversidad en el planeta ha gozado de una relativa estabilidad en lo referente al número de especies y que ha sido en el último milenio, y más intensamente a partir de la generalización planetaria de la revolución industrial, cuando hemos empezado a detectar un proceso de pérdida de especies, de hábitats y de procesos ecológicos fundamentales que reportan bienes y servicios básicos fundamentales para la humanidad.

Los sistemas productivos concentrados, de monocultivo y altamente especializados, propios de la industrialización, han desplazado y sustituido a numerosos agroecosistemas locales que mantenían en muchos casos una excelente relación con el medio natural.

La difusión de la ciudad, la fragmentación de hábitats, y la hegemonía urbana -por cierto, desde el pasado año 2008 la humanidad, por primera vez en la historia, vive ya mayoritariamente en las ciudades- han contribuido a simplificar y banalizar la diversidad agraria y han afectado muy negativamente a la diversidad silvestre.

1 Ministra de Medio Ambiente y Medio Rural y Marino. Gobierno de España. 
Y, por último, el uso mayoritario de energías fósiles, responsable tanto de importantes mejoras en el desarrollo humano como de graves desequilibrios en la generación y acceso al bienestar, es también la principal causa del cambio climático y de la cohorte de problemas ambientales.

Todo ello activó a la Organización de la Naciones Unidas para iniciar, a finales de los noventa, un ambicioso proyecto de Evaluación de los Ecosistemas del Milenio. En sus primeros informes y análisis, publicados en 2005, se alertó de los graves impactos ambientales que nuestros estilos de vida están provocando a nivel planetario y local.

Los primeros documentos de la Evaluación concluían también que esas alteraciones de los ecosistemas estaban mermando la capacidad para producir los bienes y servicios de los que dependen en última instancia no sólo las economías de la humanidad sino la vida misma tal como la conocemos.

Asimismo, los resultados obtenidos en las primeras evaluaciones de los objetivos fijados para 2010 parecen indicar que estamos lejos de poder manifestarnos optimistas. Pero es cierto también que se percibe como reacción positiva un aumento de la concienciación y la preocupación social por los problemas ambientales. Y es esa mayor concienciación de la ciudadanía en la que ahora debemos apoyarnos para ser más ambiciosos y actuar con mayor eficacia en la lucha contra la pérdida de biodiversidad.

Nuestro país, y por extensión Europa, es un territorio diverso en el que, probablemente más que en ningún otro continente, la mano del hombre ha tenido gran trascendencia y un efecto benefactor para la conformación de algunos paisajes singulares y para conformar ecosistemas, o más exactamente agroecosistemas, de indudable valor ecológico.

La gran diversidad de las especies europeas, y las múltiples interacciones entre cultivos y hábitats, entre agrobiodiversidad y razas ganaderas, entre especies silvestres y aprovechamientos silvopastorales, tienen en común procesos y flujos, sistemas de propiedad y aprovechamiento de la tierra, procesos culturales en definitiva acompasados por un uso extensivo y una adaptación local de comunidades rurales que, durante siglos, milenios incluso, supieron configurar unos códigos locales de manejo -que, por cierto, también se están extinguiendo- de los que dependía el mantenimiento de todo un entramado que vinculaba paisaje, producción agroalimentaria local, comercialización singularizada y mantenimiento de la diversidad natural y cultural.

Estos ejemplos históricos de buenas prácticas, a los que la FAO se refiere como lugares y sitios donde nos encontramos con "sistemas ingeniosos del patrimonio agrícola mundial”, merecen ser preservados, conocidos y reconocidos en cada país, en cada región, en cada comarca, con el fin de establecer las bases para el manejo sustentable de los mismos para proteger así, y de forma conjunta, la biodiversidad 16 genética, taxonómica y ecosistémica y su sistema de conocimiento local asociado. 
El 27\% de la superficie de España está incluida en la Red Natura 2000. En muchos de estos lugares la intervención humana es origen y causa de sus extraordinarios valores de conservación, pudiéndose citar como caso paradigmático las dehesas del suroeste de la Península Ibérica. La continuidad actualizada, revitalizada y rehabilitada de los métodos vernáculos y tradicionales de gestión de la tierra y del suelo que nos dejaron en herencia las comunidades campesinas del pasado resulta fundamental para la supervivencia de muchas especies, tanto silvestres como domésticas.

Éste es un diagnóstico de situación que se comparte ya mayoritariamente en los ambientes científicos y políticos. En cualquier caso no se trata enfocar la solución dando marcha atrás al reloj de la historia, eso es evidente. Se trata de reconocer el valor y el papel imprescindible que pueden jugar los sistemas culturales locales -poco estudiados, cuando no desestimados en un pasado no demasiado lejano- en la conservación de nuestro patrimonio natural.

Aplicar ingenio e innovación para leer lo que la historia y la biogeografía nos están diciendo debería ser un ejercicio cotidiano en la gestión de los espacios naturales. No en vano la supervivencia de muchas especies y hábitats amenazados dependen que logremos incorporar el conocimiento inherente a los métodos tradicionales de manejo de la tierra al diseño y aplicación de los modernos modelos de gestión.

Con esta intención de buscar un reequilibrio entre las políticas de desarrollo y las de conservación que las hiciera más interdependientes, y más eficaces, el Gobierno de España acometió en la última legislatura una importante reforma de estructura para vincular bajo un mismo departamento competencias y áreas netamente productivas, en los campos de la agricultura, el agua, la pesca, la ganadería y la silvicultura, con competencias y objetivos de conservación del patrimonio natural y la biodiversidad.

El resultado de esta reforma se inicia con la creación del Ministerio de Medio Ambiente y Medio Rural y Marino.

La apuesta inequívoca del Ministerio, y del resto de departamentos ministeriales del gobierno, se centra en trabajar por la consolidación de los procesos de desarrollo sostenible.

Por una parte, estamos introduciendo reformas en las políticas de desarrollo con ese objetivo y, por otra, estamos tratando de hacer más activas las políticas de conservación para que desplieguen nuevos instrumentos de gestión.

Ya no basta con declarar espacios o especies protegidas y esperar a que tal declaración surta efecto por sí misma. Es cierto que la declaración de un área protegida contribuye a preservar el medio y el territorio de la vorágine del crecimiento urbanístico, o de otros cambios radicales de uso del suelo, pero sin embargo no la protege de los riesgos derivados del despoblamiento y del abandono de los usos tradicionales que durante siglos permitieron un equilibrio complejo entre el aprovechamiento 
-rentable- de los recursos y la conservación de entornos de un extraordinario valor natural.

La conservación de la biodiversidad en la escala local requiere, en consecuencia, planificación, gestión, aprovechamiento de las rentas naturales y conversión en bienes y servicios de interés doble para el consumidor comprometido con la conservación de los ecosistemas y para la conservación de los procesos agroecológicos esenciales.

En el orden institucional, se precisa una buena coordinación entre ámbitos competenciales sectoriales y territoriales, desde el ámbito internacional y de la Unión Europea, como en cada Comunidad Autónoma y en cada una de las administraciones locales, de manera que cada problema se resuelva y se canalice en la escala y el escenario adecuados.

Nuestro país trabaja por igual en la defensa de la biodiversidad en el ámbito nacional, entre otras maneras con un especial interés por el impulso de las leyes de fomento del desarrollo sostenible del medio rural y la de conservación del patrimonio natural y la biodiversidad, como en internacional.

De igual manera nuestra preocupación por la conservación de los caladeros y las especies marinas, la recuperación de las mismas, el impulso a las reservas marinas, la conservación de los recursos fitogenéticos de interés agroalimentario, o las razas ganaderas autóctonas, se combinan con la defensa de los hábitats naturales las especies silvestres, las mejoras en eficiencia y eficacia en la gestión de las explotaciones o la lucha contra el cambio climático y la promoción del uso de energías locales renovables, entre otras prácticas de uso sostenible de los recursos.

Las respuestas internacionales para frenar la pérdida de biodiversidad tienen un referente básico en el Convenio de las Naciones Unidas sobre Diversidad Biológica de las Naciones Unidas (CDB).

EI CDB y la cumbre de Johannesburgo sobre desarrollo sostenible del año 2002, respaldaron establecer el objetivo de reducir de forma significativa la pérdida de biodiversidad en el año 2010. Desde 2004, esta meta forma parte, además, de uno de los ocho Objetivos de Desarrollo del Milenio adoptados en los que se trabaja con el fin último de conseguir el alivio de la pobreza en el mundo.

El objetivo de «gestionar los recursos naturales de forma más responsable: proteger y recuperar hábitats y sistemas naturales y frenar la pérdida de biodiversidad para 2010» ha de tener continuidad en el futuro, y es necesario adoptar, a todos los niveles de gobierno, una Meta post-2010 en materia de biodiversidad que garantice también el alivio de la pobreza y el bienestar humano. La revisión de los resultados en el objetivo actual, para 2010, previsiblemente aconsejará la introducción de importantes modificaciones, no tanto en los aspectos ideológicos que lo justifican, sino en la búsqueda de los 18 mejores itinerarios y compromisos para alcanzar los éxitos necesarios. 
Nuestro país está comprometido con estos objetivos por lo que en la Presidencia española de la Unión Europea, en el primer semestre de 2010, se trabajará con intensidad para dar el necesario impulso y adoptar, con los demás países europeos, las medidas necesarias para poner freno a la pérdida de biodiversidad.

En ese camino, en esa búsqueda, les anticipo que pueden contar con la colaboración del Gobierno de España. 

NuESTRA RIQUEZA

da NATURAL 
